\title{
Is right ventricular function the one that matters in ARDS patients? Definitely yes
}

Received: 10 September 2008

Accepted: 11 September 2008

Published online: 7 October 2008

(C) Springer-Verlag 2008

This editorial refers to the article available at: doi:10.1007/s00134-008-1307-1.

\author{
A. Vieillard-Baron (我) \\ Intensive Care Unit, Assistance Publique des Hôpitaux de Paris, \\ University Hospital Ambroise Paré, 9, Avenue Charles-de-Gaulle, \\ 92104 Boulogne, France \\ e-mail: antoine.vieillard-baron@apr.aphp.fr \\ Tel.: +33-149095605 \\ Fax: +33-149095892
}

A. Vieillard-Baron

Faculté de Paris Ile-de-France Ouest, Université de Versailles Saint Quentin en Yvelines, Versailles, France

Since the beginning of the 1980s, intensivists have known that acute respiratory distress syndrome (ARDS) is strongly associated with pulmonary hypertension and right ventricular $(\mathrm{RV})$ dysfunction $[1,2]$. Three phenomena promote this. First, lung damage per se, which combines alveolar injury with capillary destruction and obstruction by clots. Second, remodeling of the pulmonary circulation, defined as a muscularization of normally nonmuscularized vessels, mediated by hypoxemia and hypercarbia, and finally, positive pressure ventilation, which increases the distending pressure of the lung and thus crushes the pulmonary capillaries. These phenomena are reversible, except for pulmonary capillary destruction, which was especially observed when tidal volume was adjusted to correct the $\mathrm{PaCO}_{2}$, and so the plateau pressure $\left(P_{\text {plateau }}\right)$ is not limited. During this period, RV failure was frequent and associated with high mortality [2-4]. In particular, Jardin et al. found in a series of 23 patients an incidence of acute cor pulmonale (ACP) as high as $61 \%$ with $100 \%$ mortality in the most severe forms [2]. ACP is considered to reflect RV dysfunction due to an acute increase in RV afterload, as in ARDS. Its definition is echocardiographic: RV dilatation in combination with paradoxical septal motion during systole.

Following the ARDS network study, which demonstrated the beneficial effect of limiting $P_{\text {plateau }}$ [5], the question was whether RV dysfunction is a dreaded complication of the past or is still very much with us [6]. This debate is of importance when two very different ventilatory approaches are compared: an "open-lung approach" requiring significant lung-distending pressures in inspiration and also in expiration to "recruit" the lung, but likely to impair the right ventricle [7], and a "RV protective approach," more designed to preserve the right ventricle [8].

In 2001, we reported a series of 75 ARDS patients submitted to low-stretch ventilation, which combines a low positive end-expiratory pressure (PEEP) (mean $7 \mathrm{~cm} \mathrm{H}_{2} \mathrm{O}$ ) and a $P_{\text {plateau }}$ below $27 \mathrm{~cm} \mathrm{H}_{2} \mathrm{O}$, and in whom we looked for the presence of ACP [9]. We found two main results: first, a 25\% incidence of ACP, which is significantly lower than that in older studies, and second, no difference in mortality $(32 \%)$ in patients with and without ACP [9]. Our results were understood and interpreted by others as indicating that RV dysfunction has now become infrequent and has no impact on prognosis in ARDS patients. This is a terrible error, as well demonstrated by Osman et al. [10]. Using the database of their previous study on the pulmonary artery catheter [11], they demonstrate that RV dysfunction, defined by a central venous pressure (CVP) higher than the pulmonary artery occlusion pressure (PAOP), is a major prognostic factor in ARDS patients [10]. The incidence of this hemodynamic profile was $27 \%$, as 
shown in Table 3 of their study. Although obtained by using a nonoptimal way of diagnosing RV dysfunction, the best one being echocardiography, their results are convincing. But, how to reconcile their results with our 2001 study? Very simple. In our study, we responded to any observation of ACP by immediately making significant adjustments in respiratory management [9]. In particular, $P_{\text {plateau }}$ and PEEP were decreased further, if possible, and prone positioning, a maneuver known to have a positive effect on lung mechanics and so on RV function [12], was largely applied (in 63\% of patients with ACP but in only $14 \%$ of patients without ACP). Conversely, Osman et al. performed a strict observational study, and the definition of RV dysfunction and the statistical analysis are retrospective. Consequently, no recommendation was made for intensivists in the case of RV dysfunction. For instance, we do not know how many and which patients were turned into the prone position in this study. Finally, the comparison of these two studies clearly demonstrates that the impact of RV dysfunction on prognosis can be limited, but providing that the deleterious effects of mechanical ventilation on $\mathrm{RV}$ function are strictly controlled. A right ventricle that is already injured because of the lung process is unable to tolerate and adapt to aggressive ventilation. A recent study on a large series of ARDS patients confirms this assertion [13]. It found that the incidence of ACP and its impact on prognosis were strongly related to the range of $P_{\text {plateau }}$ : in patients with a $P_{\text {plateau }}$ below $27 \mathrm{~cm} \mathrm{H}_{2} \mathrm{O}$, the incidence of ACP was low-between 10 and $15 \%$ and its impact on mortality was nil, whereas in patients with a $P_{\text {plateau }}$ between 27 and $35 \mathrm{~cm} \mathrm{H}_{2} \mathrm{O}$ the incidence of ACP was close to $35 \%$ and had a significant impact on mortality [13]. In the study by Osman et al., it would be interesting to know the prognostic impact of RV dysfunction not only in the whole population but also within different ranges of $P_{\text {plateau }}$.
However, the study by Osman et al. is not totally clear. In particular, it is difficult to understand why the combination of a mean pulmonary artery pressure higher than $25 \mathrm{mmHg}$ plus a CVP higher than the PAOP plus a low stroke index did not appear as a prognostic factor [10]. This is more sensitive to greater severity than a CVP higher than PAOP only. This reflects RV failure more than RV dysfunction. One of the explanations, given by the authors, is that when faced with this situation intensivists are more fully alerted to the severity of the disease because of the associated low-flow state and therefore modify the ventilatory and hemodynamic strategies. However, the results presented in the study do not allow a definitive conclusion to be drawn in this regard and a statistical problem is not excluded. Moreover, this may reflect a limitation of pulmonary artery catheterization, which renders difficult the interpretation of a hemodynamic profile with finesse in a real-life situation, where intensivists are mainly focused on cardiac output. Interestingly, and not surprisingly, patients with RV failure had more severely injured lungs with much lower compliance of the respiratory system [10], illustrating once again the impact of the combination lung damage/ positive pressure ventilation on pulmonary circulation and then on RV function.

To conclude, this study and previous studies allow us to claim that daily RV function assessment is mandatory for the management of ARDS patients, especially in the most severe cases. This is now recommended by the French Society of Intensive Care Medicine (SRLF) [14]. Although not really the theme of this editorial, it is important to maintain that the best method for evaluating RV function is echocardiography [15]. Any observation of RV dysfunction, whatever be the cardiac output, should prompt intensivists to adapt their ventilatory management, by decreasing $P_{\text {plateau }}$ and limiting PEEP and by using prone positioning.

\section{References}

1. Zapol W, Snider M (1977) Pulmonary hypertension in severe acute respiratory failure. N Engl J Med 296:476-480

2. Jardin F, Gueret P, Dubourg O, Farcot JC, Margairaz A, Bourdarias JP (1985) Two-dimensional echocardiographic evaluation of right ventricular size and contractility in acute respiratory failure. Crit Care Med 13:952-956

3. Squara P, Dhainaut JF, Artigas A, Carlet J (1998) Hemodynamic profile in severe ARDS: results of the European Collaborative ARDS study. Intensive Care Med 24:1018-1028
4. Monchi M, Bellenfant F, Cariou A, Joly LM, Thebert D, Laurent I, Dhainaut JF, Brunet F (1998) Early predictive factors of survival in the acute respiratory distress syndrome. A multivariate analysis. Am J Respir Crit Care Med 158:1076-1081

5. The Acute Respiratory Distress Syndrome Network (2000) Ventilation with lower tidal volumes as compared with traditional tidal volumes for acute lung injury and the acute respiratory distress syndrome. N Engl J Med 342:1301-1308
6. Scherrer-Crosbie M, Streckenbach SC, Zapol W (2001) Acute cor pulmonale in acute respiratory distress syndrome: a dreaded complication of the past? Crit Care Med 29:1641-1642

7. Borges J, Okamoto V, Matos G, Caramez M, Arantes P, Barros F, Souza C, Victorino J, Kacmarek R, Barbas C, Carvalho C, Amato M (2006)

Reversibility of lung collapse and hypoxemia in early acute respiratory distress syndrome. Am J Respir Crit Care Med 174:268-278 
8. Page B, Vieillard-Baron A, Beauchet A, Aegerter P, Prin S, Jardin F (2003) Low stretch ventilation strategy in acute respiratory distress syndrome: eight years of clinical experience in a single center. Crit Care Med 31:765-769

9. Vieillard-Baron A, Schmitt JM,

Augarde R, Fellahi JL, Prin S, Page B, Beauchet A, Jardin F (2001) Acute cor pulmonale in acute respiratory distress syndrome submitted to protective ventilation: incidence, clinical implications, and prognosis. Crit Care Med 29:1551-1555

10. Osman D, Monnet X, Castelain V, Anguel N, Warszawski J, Teboul JL, Richard C; for the French Pulmonary Artery Catheter Study Group (2008) Incidence and prognostic value of right ventricular failure in acute respiratory distress syndrome. Intensive Care Med. doi:10.1007/s00134-008-1307-1
11. Richard C, Warszawski J, Anguel N, Deye N, Combes A, Barnoud D, Boulain T, Lefort Y, Fartoukh M, Baud F, Boyer A, Brochard L, Teboul JL (2003) Early use of the pulmonary artery catheter and outcomes in patients with shock and acute respiratory distress syndrome: a randomized controlled trial. JAMA 290:2713-2720

12. Vieillard-Baron A, Charron C, Caille V, Belliard G, Page B, Jardin F (2007) Prone positioning unloads the right ventricle in severe ARDS. Chest 132:1440-1446

13. Jardin F, Vieillard-Baron A (2007) Is there a safe plateau pressure in ARDS? The right heart only knows. Intensive Care Med 33:444-447
14. Richard JC, Girault C, Leteurtre S, Leclerc $\mathrm{F}$, for the experts group of the SRLF (2005) Ventilatory management of acute respiratory distress syndrome in adult patients and children (new-born excepted). Société de réanimation de langue française experts recommendations. Réanimation 14:313-322

15. Vieillard-Baron A, Prin S, Chergui K, Dubourg O, Jardin F (2002) Echo-Doppler demonstration of acute cor pulmonale at the bedside in the medical intensive care unit. Am J Respir Crit Care Med 166:1310-1319 